\title{
Microbiological, Chemical, and Sensory Characteristics of Swiss Cheese Manufactured with Adjunct Lactobacillus Strains Using a Low Cooking Temperature
}

\author{
N. A. Kocaoglu-Vurma, ${ }^{*}$ W. J. Harper, ${ }^{*}$ M. A. Drake,† and P. D. Courtney ${ }^{* 1,2}$ \\ *Department of Food Science and Technology, The Ohio State University, Columbus 43210 \\ †Department of Food Science, Southeast Dairy Foods Research Center, North Carolina State University, Raleigh 27695
}

\begin{abstract}
The effect of nonstarter Lactobacillus adjunct cultures on the microbial, chemical, and sensory characteristics of Swiss cheese manufactured using the "kosher make procedure" was investigated. The kosher make procedure, which uses a lower cooking temperature than traditional Swiss cheese making, is used by many American cheese manufacturers to allow for koshercertified whey. Cheeses were manufactured using a commercial starter culture combination and 1 of 3 nonstarter Lactobacillus strains previously isolated from Swiss cheeses, Lactobacillus casei A26, L. casei B21, and Lactobacillus rhamnosus $\mathrm{H} 2$, as an adjunct. Control cheeses lacked the adjunct culture. Cheeses were analyzed during ripening for microbial and chemical composition. Adjunct strain L. casei A26, which utilized citrate most readily in laboratory medium, dominated the Lactobacillus population within $30 \mathrm{~d}$, faster than the other adjunct cultures. There were no significant differences in Propionibacterium counts, Streptococcus thermophilus counts, protein, fat, moisture, salt, and $\mathrm{pH}$ among the cheeses. Free amino acid concentration ranged from 5 to $7 \mathrm{mmol} / 100 \mathrm{~g}$ of cheese at $90 \mathrm{~d}$ of ripening and was adjunct strain dependent. Lactic, acetic, and propionic acid concentrations were not significantly different among the cheeses after a 90 -d ripening period; however differences in propionic acid concentrations were apparent at $60 \mathrm{~d}$, with the cheeses made with $L$. casei adjuncts containing less propionic acid. Citric acid was depleted by the end of warm room ripening in cheeses manufactured with adjunct $L$. casei strains, but not with adjunct $L$. rhamnosus. Cheeses made with $L$. casei A26 were most similar to the control cheeses in diacetyl and butyric/isobutyric acid abundance as evaluated by electronic nose during the first
\end{abstract}

Received August 8, 2007

Accepted February 25, 2008.

${ }^{1}$ Corresponding author: courtney.polly@heb.com

${ }^{2}$ Current address: H-E-B Grocery Company, Quality Assurance \& Environmental Affairs, 5105 Rittiman Road, San Antonio, TX 78218.
3 mo of ripening. The 4 cheese types differed in their descriptive sensory profiles at $8 \mathrm{mo}$ of age, indicating an adjunct strain-dependent effect on particular flavor attributes. Adjunct Lactobacillus spp. affected the flavor profile and concentration of some flavor compounds in Swiss cheeses produced with the kosher make procedure. Use of adjunct Lactobacillus cultures provides Swiss cheese makers using a low cooking temperature with a means to control the dominant Lactobacillus strain during ripening, reduce citrate concentration, and modify cheese flavor.

Key words: Swiss cheese, adjunct culture, Lactobacillus casei, citrate

\section{INTRODUCTION}

The effect of nonstarter lactobacilli on cheese quality can be positive, negative, or neutral depending on the strains that predominate and their roles during ripening (Crow et al., 2001; Swearingen et al., 2001; Kieronczyk et al., 2003). High concentrations of desirable nonstarter lactobacilli in cheese throughout ripening provide balanced flavor development and minimize the possible effects of undesirable nonstarter lactic acid bacteria (Crow et al., 2001); therefore, many cheese makers advocate adding adjunct Lactobacillus cultures during cheese making. Experimental cheeses containing adjunct lactobacilli show improved flavor intensity and acceptability and higher levels of free amino acids when compared with control cheeses (Lynch et al., 1997).

In Switzerland, facultatively heterofermentative adjunct Lactobacillus spp. are used in the Swiss cheese industry to retard propionic acid fermentation and to prevent late fermentation in Emmental cheese (Fröhlich-Wyder et al., 2002). Although the use of Lactobacillus casei as an adjunct culture is common for Swisstype cheese manufactured in Switzerland, few published reports exist on adjunct use in Swiss cheese and none exist for adjunct use in US-manufactured Swisstype cheese. Traditional Swiss cheese making involves cooking the curds in the whey at 51 to $58^{\circ} \mathrm{C}$ (Reinbold, 
1972). With the "kosher make procedure," cooking temperatures must be $\leq 49^{\circ} \mathrm{C}$ to allow for kosher certification of whey products derived from cheese making. This alteration in cooking temperature causes changes in the final cheese quality, such as rapid acid development, increased split defects, and high moisture (B. Ramseyer, Holmes Cheese Co., Millersburg, OH; personal communication; G. Hong, Brewster Dairy Inc., Brewster, $\mathrm{OH}$; personal communication). Adjunct culture addition has the potential to reduce vat-to-vat variability within the same manufacturing facility and would allow the cheese maker to control, to some extent, the effect of nonstarter bacteria on cheese quality. The objective of this study was to examine the effect of adjunct Lactobacillus strains on the chemical and sensory properties and culture dynamics of Swiss cheeses manufactured using the kosher make procedure.

\section{MATERIALS AND METHODS}

\section{Bacterial Strains}

Streptococcus thermophilus STC-6, Lactobacillus helveticus Lh-32, and Propionibacterium freudenreichii ssp. shermani PS-4 cultures (Chr. Hansen Inc., Milwaukee, WI) were used as direct-vat-set starter cultures. Adjunct cultures were selected from previously isolated nonstarter lactobacilli based on their citrate utilization properties in broth and on agar plates (KocaogluVurma, 2005). Lactobacillus casei A26 isolated from Swiss Emmental utilizes citrate. Lactobacillus rhamnosus $\mathrm{H} 2$ and $L$. casei $\mathrm{B} 21$ were both isolated from USmanufactured Swiss cheeses and metabolize little or no citrate, respectively, in laboratory medium. The maximum specific growth rates for $L$. casei $\mathrm{A} 26$ and $L$. rhamnosus $\mathrm{H} 2$ in a basal medium containing $30 \mathrm{mM}$ citrate were 0.22 and $0.07 \mathrm{~h}^{-1}$, respectively. Growth was not detected for L. casei B21 in this medium (KocaogluVurma, 2005).

Nonstarter Lactobacillus cultures were grown to stationary phase (18 h) in Lactobacillus de Man, Rogosa, Sharpe broth (Criterion, Hardy Diagnostics, Santa Maria, CA), washed twice in sterile PBS, and resuspended in sterile water immediately before inoculation into the cheese milk. Cultures were inoculated to approximately $10^{3} \mathrm{cfu} / \mathrm{mL}$ of milk to achieve $>10^{5} \mathrm{cfu} / \mathrm{g}$ of cheese before brining.

\section{Cheese Manufacture}

Twelve cheeses (triplicates of 4 treatments) were manufactured in 200-L-capacity pilot-scale cylindrical cheese vats (C. van't Riet Dairy and Process Equipment, Aarlanderveen, the Netherlands) by using the rindless block procedure modified to simulate the kosher make procedure (Reinbold, 1972; Kosikowski and Mistry 1997). The pilot-scale procedure was developed in consultation with 2 Swiss cheese companies that have used this procedure commercially. Milk $(100 \mathrm{~L})$ from the Ohio State University Dairy Farm (Columbus, $\mathrm{OH}$ ) was standardized to a 1:1 true protein-to-fat ratio and pasteurized in the vat by holding at $63^{\circ} \mathrm{C}$ for $30 \mathrm{~min}$. Before inoculation with starter cultures, the milk temperature was reduced to $34.4^{\circ} \mathrm{C}$ with gentle to moderate stirring. Nonstarter Lactobacillus cultures were added to achieve approximately $10^{3} \mathrm{cfu} / \mathrm{mL}$ of milk. Starter cultures were added at the levels recommended by the culture supplier. To accomplish this, a 15-g sample of the starter culture pellets was thawed in a sterile container and thoroughly mixed. The recommended amount (STC-6, $60 \mathrm{mg}$; Lh-32, $120 \mathrm{mg}$; PS-4, $300 \mathrm{mg}$ ) was aseptically removed and inoculated into the milk. Inoculated milk was ripened for $20 \mathrm{~min}$ and then set with $8 \mathrm{~g}$ of coagulant (Chy-max Extra, Chr. Hansen Inc.) diluted in $40 \mathrm{~mL}$ of sterile water. After 25 to 30 min, the curd was cut slowly to fine curd size (6 to 8 $\mathrm{mm}$ ) by rotating the 2 cutting blade frames (with blades fixed at $37 \mathrm{~mm}$ apart) at a gradually decreasing rate over $10 \mathrm{~min}$. The rotation rate for cutting was controlled by using an automated speed control unit. The curds were then heated to $47.5^{\circ} \mathrm{C}$ for approximately $30 \mathrm{~min}$, and held at $47.5^{\circ} \mathrm{C}$ with gentle agitation until the target curd $\mathrm{pH}$ value of 6.45 to 6.55 was reached. The whey and the curd were pumped into perforated stainless steel vessels dressed with disposable cheesecloth. The whey was drained by gradually adding weight (up to $20 \mathrm{~kg}$ ) to create approximately $2 \mathrm{~kg}$ of pressure/ $\mathrm{kg}$ of cheese. The cheese was pressed at $37^{\circ} \mathrm{C}$ until the cheese $\mathrm{pH}$ decreased to approximately 5.25. A sample was taken from the center for $\mathrm{pH}$ and microbiological analysis. Subsequently, the cheese (approximately $36 \times 26 \times$ $8 \mathrm{~cm}$ ) was divided into 4 equally sized blocks (approximately $18 \times 13 \times 8 \mathrm{~cm}$ ) and placed into brine solution (23\% salt, $0.001 \% \mathrm{CaCl}_{2}$, pH 5.4, 4 to $7^{\circ} \mathrm{C}$ ) for $4 \mathrm{~h}$. After brining, the blocks were vacuum-packaged in 3-mil nylon-polyethylene standard barrier vacuum pouches and stored at 4 to $7^{\circ} \mathrm{C}$ for $6 \mathrm{~d}$ to allow for salt equilibration throughout the block. After this precooling step, blocks were placed into plastic molds and stored in a warm room $\left(21\right.$ to $\left.22^{\circ} \mathrm{C}\right)$ for Propionibacterium growth. After $24 \mathrm{~d}$ in the warm room, cheeses were transferred to cold storage at 4 to $7^{\circ} \mathrm{C}$ for 2 to $8 \mathrm{mo}$ for ripening. One of the 4 blocks was removed for sampling at $6,30,60$, and $90 \mathrm{~d}$.

In addition to standard cleaning and chemical sanitizing, all cheese-making equipment (milk cans, cheese vats, stirrers, knives, cheesecloth, and pressing tables) was steam-sterilized before each cheese-making session to eliminate or minimize environmental contamination 
and carryover of adjunct strains from day to day. Brine solution was prepared as a large batch and divided into 4 containers. Each container was designated for use with one adjunct treatment or control to avoid carryover of adjunct strains in the brine.

\section{Cheese Sampling}

Samples were taken on d 1 (before brining), d 6 (end of precooling), $d 30$ (end of the warm room), and d 60 and 90 for $\mathrm{pH}$, free amino acid concentration, organic acid content, electronic nose, and microbial analyses. Compositional analyses were performed only on mature cheeses (d 60). For microbiological analysis and $\mathrm{pH}$ measurements, a core sample was taken from the center of the cheese block. For all other analyses, one quarter of the cheese block was finely shredded and mixed to obtain uniformity. For descriptive sensory analysis, 90$\mathrm{d}$ cheeses were vacuum-packaged after removing one quarter of the cheese for other analyses and stored in the cold room $\left(4\right.$ to $\left.7^{\circ} \mathrm{C}\right)$ for a total of $8 \mathrm{mo}$ from manufacturing.

\section{Microbiological Analyses}

Total Lactobacillus spp. and total bacterial counts were determined in cheese milk after pasteurization by using Rogosa SL agar (Difco, Becton, Dickinson, and Co., Sparks, MD) and plate count agar (Difco), respectively. The adjunct and starter culture bacteria were also enumerated by taking milk samples after culture addition.

To monitor the starter population in cheeses, a 1-g sample of cheese was aseptically removed from the center of the cheese block and placed in $9 \mathrm{~mL}$ of a sterile $2 \%$ sodium citrate (Fisher Scientific, Hampton, NH) solution and stomached at high speed for $2 \mathrm{~min}$ (Seward Stomacher Biomaster 80, Seward Co., Norfolk, UK). Subsequent 10-fold serial dilutions were prepared in $0.1 \%$ peptone water (Difco). Total lactobacilli were enumerated on Rogosa SL agar (Difco) incubated anaerobically for $2 \mathrm{~d}$ at $37^{\circ} \mathrm{C}$. Streptococcus thermophilus was enumerated on M17 agar (Difco) containing 0.5\% lactose (Difco) and $0.15 \%$ lithium chloride (Fisher Scientific) incubated for $2 \mathrm{~d}$ at $42^{\circ} \mathrm{C}$, and propionibacteria were enumerated on lithium glycerol agar (Madec et. al., 1996) incubated anaerobically for $7 \mathrm{~d}$ at $30^{\circ} \mathrm{C}$.

To monitor the adjunct culture population in cheeses during storage, 100 colonies were randomly selected from Rogosa SL plates at each sampling time and inoculated onto citrate differential medium (Kempler and McKay, 1980), esculin cellobiose agar (Hunger, 1986), and modified de Man, Rogosa, Sharpe agar, with gluconate $(2 \% \mathrm{wt} / \mathrm{vol})$ replacing glucose and bromocresol pur- ple $(0.005 \%)$ added as a $\mathrm{pH}$ indicator. Each adjunct culture used in cheese manufacture showed a distinct colony appearance on these media. The presence of a colony color pattern indiscernible from that of the adjunct culture added suggested that the isolates tested were the adjunct culture added and not other contaminating nonstarter lactobacilli. Colony colors of starter and adjunct Lactobacillus strains on each media are listed in Table 1.

\section{Chemical Analyses}

Protein and fat contents were determined by using near-infrared spectroscopy (Near Infrared Analyzer KJT270, Kett US, Villa Park, CA). Moisture content was measured by using the vacuum oven method (method 926.08; AOAC, 2005). Salt content was determined potentiometrically with a silver electrode by using a Chloride Analyzer 926 (Nelson Jameson, Marshfield, WI). The $\mathrm{pH}$ was measured by using the quinhydrone-gold electrode method (Marshall, 1992). Free amino acid content was determined with the cadmiumninhydrin reagent in a microtiter plate assay, with Lleucine used as the standard (Folkertsma and Fox, 1992; Baer et al., 1996). Compositional measurements were performed in duplicate except for $\mathrm{pH}$, which was measured in triplicate.

Organic acids were determined by HPLC (Agilent 1100, Agilent Technologies, Palo Alto, CA) on an Aminex HPX-87H column (Bio-Rad, Hercules, CA) with a multiple-wavelength detector. Eight milliliters of grade S acetonitrile (Fisher Scientific, Hampton, $\mathrm{NH}$ ) and 0.2 $\mathrm{mL}$ of $1 \mathrm{~N} \mathrm{H}_{2} \mathrm{SO}_{4}$ (Fisher Scientific) were added to $1 \mathrm{~g}$ of grated cheese sample and mixed for $20 \mathrm{~min}$ in a rotary mixer. Cheese homogenates were then centrifuged at $7,900 \times g$ for $20 \mathrm{~min}$, and the supernatant was filtered through an MFS-13 filter (Advantec MFS, Pleasanton, CA). The volume of sample injected was $20 \mu \mathrm{L}$. The

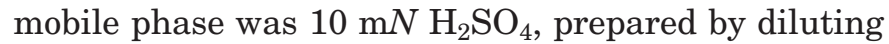
HPLC-grade $\mathrm{H}_{2} \mathrm{SO}_{4}$ (Fisher Scientific) with HPLCgrade water (Fisher Scientific) and then filtering through a $0.2-\mu \mathrm{m}$ membrane filter. The flow rate of the mobile phase was $0.6 \mathrm{~mL} / \mathrm{min}$, and the column temperature was constant at $65^{\circ} \mathrm{C}$. Peak identities were determined based on retention times of standard compounds. Concentrations of individual organic acids were quantified by using a standard curve for each compound relating peak area to concentration. Peaks were integrated and analyzed with ChemStation software (Agilent Technologies). Lactic, citric, and acetic acids were detected at $210 \mathrm{~nm}$. Acetoin and propionic acid coeluted and were both detected at this wavelength. However, propionic acid does not absorb at $290 \mathrm{~nm}$, whereas acetoin does; therefore, $290 \mathrm{~nm}$ was used to determine the 
Table 1. Colony and surrounding zone colors of starter Lactobacillus helveticus LH32 and adjunct strains Lactobacillus casei A26, L. casei $\mathrm{B} 21$, and Lactobacillus rhamnosus $\mathrm{H} 2$ on 3 agar media after $24 \mathrm{~h}$ of anaerobic incubation at $37^{\circ} \mathrm{C}$

\begin{tabular}{|c|c|c|c|}
\hline Strain & Esculin cellobiose agar & Citrate differential medium & Modified de Man, Rogosa, Sharpe medium \\
\hline L. helveticus LH32 & Light brown colony without zone & White colony without zone & Clear colony without zone \\
\hline L. casei A26 & Brown colony with gray zone & Dark blue colony without zone & Bright yellow colony with yellow zone \\
\hline L. casei $\mathrm{B} 21$ & Yellow colony with green zone & $\begin{array}{l}\text { White to light blue colony } \\
\text { without zone }\end{array}$ & Cream colony without zone \\
\hline L. rhamnosus $\mathrm{H} 2$ & Brown colony with green zone & $\begin{array}{l}\text { White colony with light blue } \\
\text { center without zone }\end{array}$ & Light yellow colony without zone \\
\hline
\end{tabular}

acetoin concentration in each cheese. The peak area of this acetoin concentration at $210 \mathrm{~nm}$ was determined from a standard curve and subtracted from the peak area at $210 \mathrm{~nm}$ containing both acetoin and propionic acid. The remaining peak area was used to calculate propionic acid concentration.

Instrumental differentiation of cheese aroma was conducted by using an Agilent Technologies Chem Sensor 4400 equipped with a headspace autosampler unit (HP 7694) and mass selective detector (MSD 5973) as a sensor operated in the negative-ionization mode, with methane as the ionizing gas. Shredded cheese samples $(3 \mathrm{~g})$ from each sampling period were placed in $20-\mathrm{mL}$ headspace vials and capped with a Teflon-faced silicon rubber cap. Triplicate samples were randomly placed in the autosampler and equilibrated at $60^{\circ} \mathrm{C}$ for $30 \mathrm{~min}$. Helium was used as the carrier gas at a pressure of 2.81 $\mathrm{kgf} / \mathrm{cm}^{2}$. One microliter of headspace was introduced in a pulsed splitless mode at $5.27 \mathrm{kgf} / \mathrm{cm}^{2}, 250^{\circ} \mathrm{C}$. The capillary column was set to $220^{\circ} \mathrm{C}$ for $6 \mathrm{~min}$. A purge time of $1.5 \mathrm{~min}$ was used between samples.

\section{Descriptive Sensory Analysis}

Eight-month-old Swiss cheeses were cut into 2.54-cm cubes for descriptive sensory analysis. The cheeses were placed into $58-\mathrm{mL}$ soufflé cups with lids labeled with 3 -digit codes. The cheeses were tempered to $10^{\circ} \mathrm{C}$ and served at this temperature. Descriptive analysis was conducted with a 15-point universal intensity scale using the Spectrum method (Meilgaard et al., 1999; Drake and Civille, 2003) and a cheese flavor sensory language modified for Swiss cheese (Drake et al., 2001; Table 2). A trained descriptive sensory panel $(\mathrm{n}=8 ; 6$ females, 2 males, ages 24 to $45 \mathrm{yr}$ ), with more than $150 \mathrm{~h}$ of experience each with descriptive analysis of cheese flavor, evaluated the cheeses. Consistent with Spectrum descriptive analysis training, panelists were presented with reference solutions of sweet, sour, salty, and bitter tastes to learn to use the universal intensity scale consistently (Meilgaard et al., 1999; Drake and Civille, 2003). After consistent use of the Spectrum scale with basic tastes, panelists learned to identify and scale flavor descriptors by using the same intensity scale through presentation and discussion of flavor definitions, references, and a wide array of cheeses. Discussion and evaluation of a wide array of cheeses (Swiss and other cheeses) was also conducted during training to enable panelists to differentiate and replicate samples consistently. Analysis of data collected from training sessions confirmed that panel results were consistent and that terms were not redundant, consistent with previous use of the developed language (Drake et al., 2001). Each replication of each cheese treatment was evaluated monadically in duplicate in a randomized balanced block design. Evaluations were conducted individually in an enclosed room dedicated to sensory analysis that was free from external aromas, noise, and distractions. Panelists were instructed to expectorate samples after evaluation. Spring water was available to each panelist for palate cleansing.

\section{Experimental Design and Statistical Analysis}

The experimental design for Swiss cheese manufacture was a truncated Latin square. Data were analyzed by using the mixed model PROC MIXED of SAS (version 9.1, SAS Institute Inc., Cary, NC), according to the following statistical model:

$$
Y_{i j k}=\mu+\beta_{i}+V_{j}+S_{k}+\varepsilon_{i j k},
$$

where $Y_{i j k}$ is the dependent variable, $\mu$ is the mean, $\beta_{i}$ is the random effect of blocks $(i=1,2,3,4,5,6), V_{j}$ is the random effect of vats $(j=1,2), S_{k}$ is the effect of strain $(j=1,2,3,4)$, and $\varepsilon_{i j k}$ is the error term. Comparison of mean differences was analyzed by using the Tukey test $(P<0.05)$.

Sensory data were analyzed by using the general linear model (PROC GLM) of SAS. Comparison of means was performed by using Fisher's least significant difference (LSD) test $(P<0.05)$.

\section{RESULTS AND DISCUSSION}

\section{Effect of Adjunct Cultures on Microbial Composition}

Changes in the populations of Propionibacterium spp., S. thermophilus, and Lactobacillus spp. during 
Table 2. Sensory language for Swiss cheese

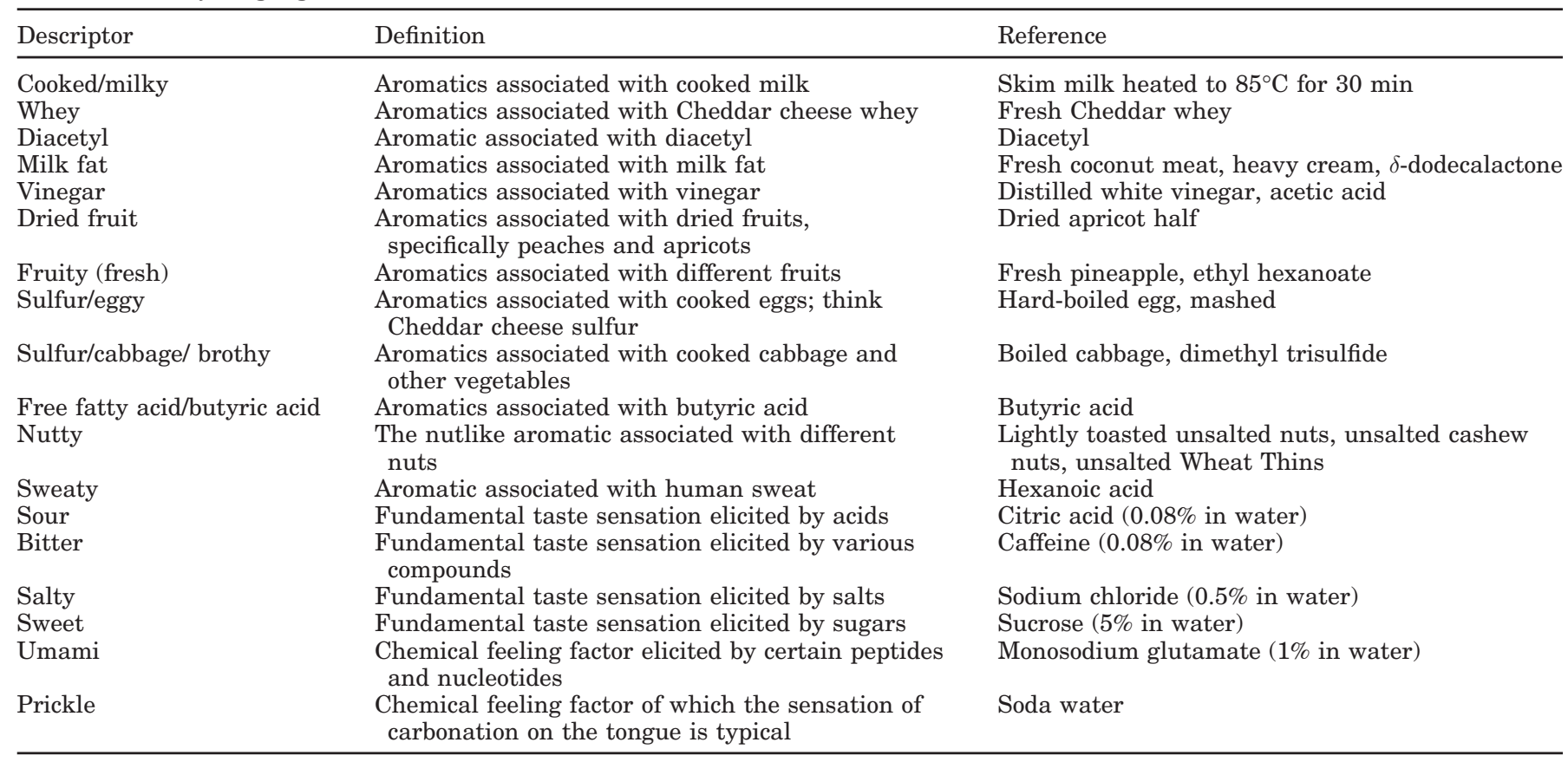

ripening in Swiss cheese manufactured with and without adjunct Lactobacillus spp. are shown in Figure 1. In all cases, the pasteurized cheese milk contained fewer than $10^{1} \mathrm{cfu} / \mathrm{mL}$ (detection limit) of Lactobacillus spp., and total aerobic plate counts were at or below $10^{2} \mathrm{cfu} / \mathrm{mL}$. The initial inoculum for all starter cultures was 4 to $5 \log \mathrm{cfu} / \mathrm{mL}$.

Propionibacterium spp. counts followed the same pattern regardless of adjunct culture. The counts increased by approximately $4 \mathrm{log} \mathrm{cfu} / \mathrm{g}$ during warm room incubation (d 6 to 30), up to 8 to $9 \mathrm{log} \mathrm{cfu} / \mathrm{g}$ of cheese, and the numbers were stable from then on. At d 90, there were no significant differences $(P \geq 0.05)$ in propionibacteria cell numbers among cheeses made with adjunct strains or the control (Figure 1A). This Propionibacterium growth pattern is typical of Swiss cheese manufacture, in which Propionibacterium spp. are inoculated at 3 to $6 \mathrm{log} \mathrm{cfu} / \mathrm{mL}$ in milk, and grow to $9 \log \mathrm{cfu} / \mathrm{g}$ of cheese during ripening in the warm room (Noël et al., 1999). Autolysis of propionibacteria is generally late and limited (Valence et al., 1998). Studies on Emmental cheese produced with and without adjunct $L$. casei strains have demonstrated that when adjunct cultures are used, Propionibacterium counts are 0.4 to 1 log lower than in control cheeses at earlier stages of ripening (Jimeno et al., 1995; Bachmann et al., 1997; Weinrichter et al., 2004b). Our results indicated that adjunct Lactobacillus strains had no significant inhibitory effect on the Propionibacterium strain used in this study. Although Propionibacterium cell numbers were not affected dra- matically, some L. casei, L. plantarum, and L. rhamnosus strains reduced the propionic acid levels at the end of ripening, suggesting that Propionibacterium metabolism may be affected (Jimeno et al., 1995; Martley and Crow, 1996; Bachmann et al., 1997; Weinrichter et al., 2004a). The influence of Lactobacillus spp. on Propionobacterium cell numbers is likely to be less important than the influence of technological parameters such as $\mathrm{pH}$ and salt in cheeses (Noël et al., 1999).

Streptococcus thermophilus levels increased to approximately $8 \mathrm{log} \mathrm{cfu} / \mathrm{g}$ of cheese during manufacturing (d 0 to 1 ) and decreased to $4 \mathrm{log} \mathrm{cfu} / \mathrm{g}$ of cheese during ripening (d 6 to 90; Figure 1B). In the control cheese and when $L$. casei B21 was used as the adjunct culture, $S$. thermophilus numbers decreased during warm room incubation (d 6 to 30). However, S. thermophilus numbers did not start decreasing substantially until after warm room incubation (after d 30) when $L$. casei A26 and $L$. rhamnosus H2 strains were used. Demarigny et al. (1996) observed similar results in a study comparing raw milk microflora with microfiltered milk microflora in Swiss-type cheeses, where $S$. thermophilus numbers decreased faster in microfiltered milk cheeses than in raw milk cheese. Dasen et al. (2003) reported an adjunct Lactobacillus strain-dependent effect on the survival of starter lactococci in Cheddar cheeses. Our results support the observation that the growth of some nonstarter lactobacilli alters the survival kinetics of starter streptococci. 


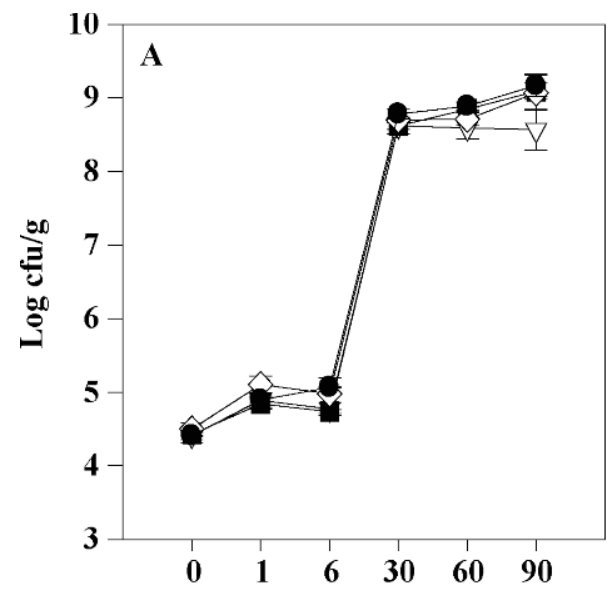

Cheese making and ripening time (days)

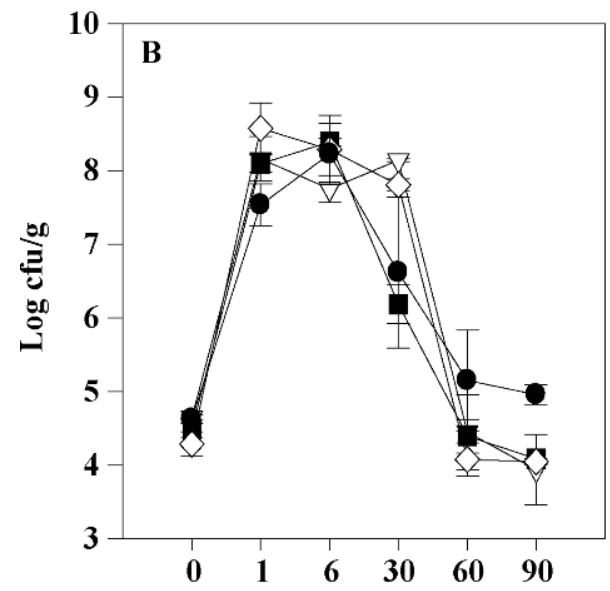

Cheese making and ripening time (days)

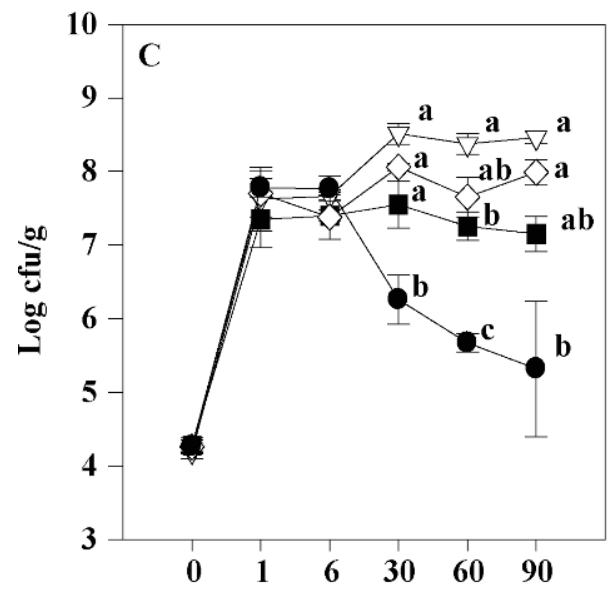

Cheese making and ripening time (days)

Figure 1. Changes in the population of Propionibacterium spp. (A), Streptococcus thermophilus (B), and Lactobacillus spp. (C) during ripening in Swiss cheese manufactured with adjunct strains Lactobacillus casei A26 $(\nabla)$, L. casei B21 (ם), Lactobacillus rhamnosus $\mathrm{H} 2$ $(\diamond)$, and without adjunct $(\bullet)$. Error bars represent \pm standard error $(\mathrm{n}=3) .{ }^{\mathrm{a}-\mathrm{c}}$ Means at the same time point (days) with the same letter are not different $(P \geq 0.05)$. No letters at a time point indicates no significant difference between the treatments.
Table 3. Percentage of Lactobacillus isolates phenotypically identical to the added adjunct culture in Swiss cheeses made with 1 of 3 adjunct cultures $^{1}$

\begin{tabular}{lccc}
\hline \multirow{2}{*}{$\begin{array}{l}\text { Days of } \\
\text { ripening }\end{array}$} & \multicolumn{3}{c}{ Adjunct culture } \\
\cline { 2 - 4 } & L. casei A26 & L. casei B21 & L. rhamnosus H2 \\
\hline 1 & $14 \pm 4$ & $1 \pm 0.5$ & $25 \pm 10$ \\
6 & $33 \pm 4$ & $5 \pm 2.5$ & $52 \pm 17$ \\
30 & $100 \pm 0$ & $69 \pm 27$ & $77 \pm 2$ \\
60 & $100 \pm 0$ & $98 \pm 1$ & $82 \pm 9$ \\
90 & $100 \pm 0$ & $100 \pm 0$ & $100 \pm 0$ \\
\hline
\end{tabular}

${ }^{1}$ Values are the mean \pm standard error $(n=3)$.

The total Lactobacillus spp. growth pattern was similar in all cheeses manufactured with an adjunct strain. The total Lactobacillus spp. population included starter L. helveticus, the adjunct Lactobacillus strain added, and any wild nonstarter Lactobacillus that may have been present in the cheese despite the precautions to prevent their introduction. In general, Lactobacillus growth occurred on the first day of cheese making ( $\mathrm{d} 0$ to 1 ), causing the cell population to increase from $4 \mathrm{log}$ $\mathrm{cfu} / \mathrm{mL}$ of milk to 7 to $8 \mathrm{log} \mathrm{cfu} / \mathrm{g}$ of cheese before brining. In cheeses prepared with an adjunct culture, the Lactobacillus population increased to 7.5 to $8.5 \mathrm{log} \mathrm{cfu} / \mathrm{g}$ by the end of warm room storage (d 30) and remained constant thereafter. In contrast, in control cheeses, the rapid increase in Lactobacillus spp. population before brining was followed by a decline in cell population during warm room storage and a decrease to 5 to $6 \mathrm{log}$ $\mathrm{cfu} / \mathrm{g}$ of cheese by the end of $90 \mathrm{~d}$ of ripening (Figure 1C). This likely reflects the growth and lysis of the $L$. helveticus starter culture. In cheeses manufactured with an adjunct Lactobacillus spp., all of the selected 100 Lactobacillus isolates were phenotypically identical to the adjunct strain added by $90 \mathrm{~d}$ of ripening, with L. casei A26 dominating the Lactobacillus population by $30 \mathrm{~d}$ (Table 3 ).

The Lactobacillus spp. growth kinetics in cheeses containing adjunct were similar to results reported in other studies, in which adjunct cultures reached a maximum level (7 to $8 \mathrm{log} \mathrm{cfu} / \mathrm{g}$ of cheese) and remained stable throughout storage. However, the majority of studies involving the use of adjunct Lactobacillus cultures have been conducted on cheeses made with mesophilic starter cultures, and thus do not contain Lactobacillus spp. in the starter culture (Lynch et al., 1997; Crow et al., 2001; Swearingen et al., 2001; Antonsson et al., 2003; Dasen et al., 2003; Agarwal et al., 2006; Ortigosa et al., 2006). Swearingen et al. (2001) studied the influence of 2 nonstarter $L$. paracasei strains on Cheddar cheese quality. The initial adjunct culture level was 4 $\log \mathrm{cfu} / \mathrm{mL}$ of milk, and Lactobacillus levels reached 7 $\log \mathrm{cfu} / \mathrm{g}$ of cheese by $7 \mathrm{~d}$ of ripening and remained high 
throughout ripening. The final concentrations reached 8 to $9 \mathrm{log} \mathrm{cfu} / \mathrm{g}$ of cheese in cheese containing adjunct. The control cheese, which lacked the adjunct cultures, initially contained approximately $1 \mathrm{log}$ cfu/g of cheese, and Lactobacillus counts gradually increased to 7 log $\mathrm{cfu} / \mathrm{g}$ of cheese within 3 mo and remained constant throughout 6 mo of ripening. In another study of addition of adjunct lactobacilli to Cheddar cheese, Dasen et al. (2003) observed a comparable increase and stability in Lactobacillus counts during ripening and a decrease in the high intertrial variability in Lactobacillus counts when adjunct lactobacilli were added. Our results indicated that, at d 90, the intertrial difference in total Lactobacillus population for cheeses manufactured with each adjunct strain was $<1 \mathrm{log} \mathrm{cfu} / \mathrm{g}$, whereas for the cheese containing no adjunct strains, the difference was $>3 \log \mathrm{cfu} / \mathrm{g}$.

The ability to utilize citrate has been reported to affect adjunct strain growth kinetics in cheese. In the present study, L. casei A26, which metabolizes citrate well in basal laboratory medium with citrate, dominated the Lactobacillus population faster than the other adjunct strains (Table 3 ). The cheeses made with $L$. casei adjunct strains were depleted of citrate after warm room ripening (see next section), suggesting that L. casei B21 is able to utilize citrate in the cheese environment despite its inability to grow in basal medium containing citrate. Lactobacillus casei B21 did not dominate the Lactobacillus population until d 60 of ripening. In contrast, the cheeses made with adjunct L. rhamnosus $\mathrm{H} 2$ were not depleted of citrate after warm room ripening, and the total Lactobacillus counts were not significantly different from those of the cheeses manufactured with adjunct $L$. casei strains (Figure 1C). Weinrichter et al. (2004a) evaluated the influence of adjunct Lactobacillus strains in 2 Swiss-type cheeses, Bergkäse and Emmental. Different from the present study, a $L$. delbrueckii strain was used in the starter culture and the standard Swiss cheese cooking temperature of $53^{\circ} \mathrm{C}$ was used. Their results indicate that citrate-utilizing adjunct strains yielded higher numbers of adjunct lactobacilli (6 to $7 \mathrm{log} \mathrm{cfu} / \mathrm{g}$ of cheese) in a shorter period of time, compared with an adjunct $L$. rhamnosus strain that could not utilize citrate.

\section{Effect of Adjunct Cultures on Cheese Chemical Composition}

The effect of adjunct cultures on various chemical aspects of Swiss-type cheese was investigated. There were no significant differences $(P \geq 0.05)$ in protein, fat, moisture, and salt-in-moisture phase (SMP) contents among the cheeses manufactured with or without ad- junct strains (Table 4). Protein, fat, and moisture contents of the cheeses were comparable to those of commercial cheese samples (Kocaoglu-Vurma, 2005). However, at 2.1 to $2.3 \%$ the SMP were higher than most US-produced commercial cheeses. French Emmental cheeses contain 0.4 to $0.7 \%$ salt ( 0.7 to $1.2 \%$ SMP based on $40 \%$ moisture), on average, although because salt distribution is not even throughout the cheese, salt levels can reach up to $1.8 \%$ (3\% SMP) in the rind (Noël et al., 1999). In the United States, Swiss cheeses with 0.8 to $3 \%$ SMP are manufactured; however, most manufacturers currently target 1.0\% SMP levels (G. Hong, Brewster Dairy Inc., Brewster, OH; personal communication).

The change in cheese $\mathrm{pH}$ during ripening is displayed in Figure 2. The d-1 cheese $\mathrm{pH}$ is particularly important because of its effect on the structural state of protein before brining and cooling. Proper eye formation is promoted between $\mathrm{pH} 5.2$ and 5.5, and $\mathrm{CO}_{2}$ production increases with $\mathrm{pH}$ (Lawrence et al., 1987). The $\mathrm{pH}$ values of d-1 cheeses ranged from 5.2 to 5.3. By the end of $90 \mathrm{~d}$ of ripening, $\mathrm{pH}$ values had increased to 5.4 to 5.5.

Total free amino acid concentration in cheese was used to indicate the extent of proteolysis. Free amino acid concentration increased 5- to 7-fold from the beginning of warm room ripening to $90 \mathrm{~d}$, with the fastest rate occurring during warm room ripening (Figure 3). Up to $60 \mathrm{~d}$ of ripening, cheeses manufactured with adjunct strain L. casei A26 followed a free amino acid development pattern similar to that of the control cheeses. The cheeses made with adjunct strains $L$. casei B21 and L. rhamnosus $\mathrm{H} 2$ were similar to each other. Initial free amino acid concentrations of the cheeses were the same $(P \geq 0.05)$. At $60 \mathrm{~d}$, cheese made with adjunct $L$. rhamnosus $\mathrm{H} 2$ had significantly lower $(P=$ 0.009) free amino acid concentrations than control cheeses and cheeses manufactured with adjunct strain L. casei A26. The free amino acid concentrations in cheeses ripened for $60 \mathrm{~d}$ were comparable to the free amino acid levels in ready-for-market commercial Swiss cheeses (Kocaoglu-Vurma, 2005). Free amino acid composition is used as a quality indicator for several cheese varieties (Poveda et al., 2004). In agreement with our results, previous research on Swiss-type cheeses revealed a higher rate of proteolysis and free amino acid liberation during warm room incubation (Baer et al., 1996; Valence et al., 2000; Ji et al., 2004). A gradual increase was observed during subsequent cold room ripening because the thermophilic lactic acid bacteria continue to lyse and release their active peptidase pool at this stage (Gagnaire et al., 2001). The rate at which the free amino acids are formed appears to be adjunct strain dependent. 
Table 4. Chemical composition of cheeses $^{1}$

\begin{tabular}{lcccc}
\hline & & & \\
Cheese $^{2}$ & Protein, \% & Fat, \% & Moisture, \% & $\begin{array}{c}\text { Salt in } \\
\text { moisture, \% }\end{array}$ \\
\hline A26 & $27.84 \pm 1.24$ & $30.97 \pm 0.39$ & $38.89 \pm 0.37$ & $2.29 \pm 0.03$ \\
B21 & $30.51 \pm 2.01$ & $29.07 \pm 0.46$ & $38.37 \pm 0.31$ & $2.16 \pm 0.10$ \\
H2 & $29.68 \pm 2.28$ & $30.63 \pm 1.79$ & $38.57 \pm 0.19$ & $2.11 \pm 0.07$ \\
Control & $28.11 \pm 0.61$ & $31.08 \pm 1.47$ & $39.68 \pm 0.93$ & $2.18 \pm 0.06$ \\
\hline
\end{tabular}

\footnotetext{
${ }^{1}$ Values are the mean \pm standard error $(\mathrm{n}=3)$.

${ }^{2}$ Cheese manufactured with adjunct Lactobacillus casei A26, L. casei B21, Lactobacillus rhamnosus H2, or with no adjunct addition (control).
}

Organic acid contents of cheeses were determined at each time point (Figure 4). Depletion of citric acid by the end of warm room incubation is desirable to minimize late fermentation by lactic acid bacteria in cold room storage, during which citrate can be consumed by nonstarter lactic acid bacteria with formation of diacetyl and $\mathrm{CO}_{2}$ (Jimeno et al., 1995). Citric acid concentrations of cheeses manufactured with $L$. casei strains as adjunct cultures were not significantly different from those of the other cheese samples before warm room ripening $(P \geq 0.05)$, and citric acid was depleted by the end of warm room ripening. Citric acid consumption was also apparent, to a lesser extent, in the control and L. rhamnosus $\mathrm{H} 2$ cheeses. The consumption of citric acid in earlier stages of ripening in control cheeses suggests citrate fermentation by the starter culture or the presence of wild citrate-fermenting lactic acid bacteria despite the precautions taken to reduce contamination. The relatively low variability in microbial counts and citrate concentration within each treatment (triplicate trials) indicates that the cause of this observation ap-

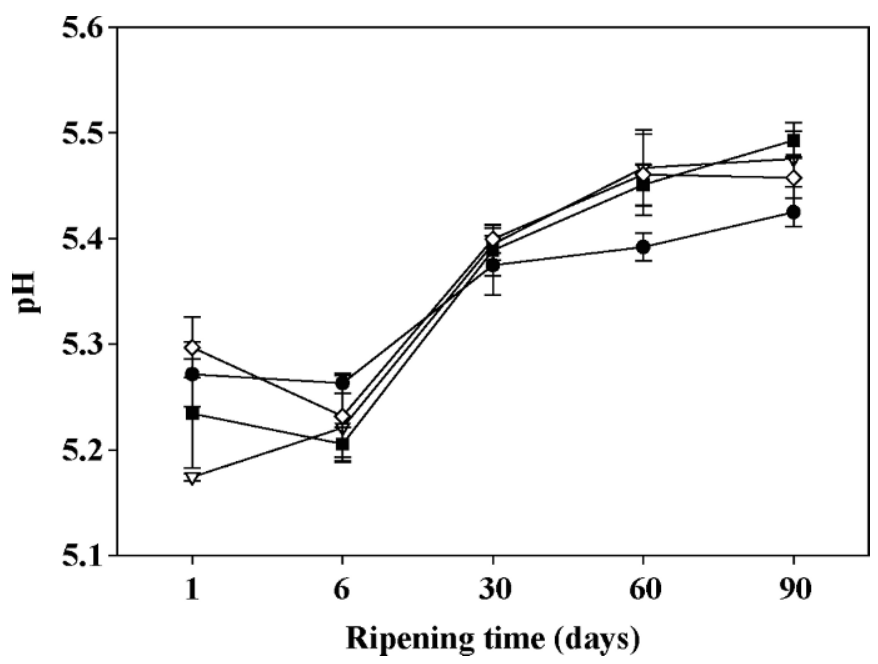

Figure 2. Changes in $\mathrm{pH}$ during ripening of cheeses manufactured with adjunct strains Lactobacillus casei A26 ( $\nabla)$, L. casei B21 (ם), Lactobacillus rhamnosus $\mathrm{H} 2(\diamond)$, and without adjunct $(\bullet)$. Error bars represent \pm standard error $(n=3)$. plied equally to all cheese-making trials and therefore did not alter our conclusions regarding adjunct cultures.

Depletion of citrate in the L. casei A26 cheeses was expected because this strain was able to grow in basal media containing citrate as the sole carbon source. Lactobacillus casei B21 was unable to grow in basal medium containing citrate, yet citrate was depleted in the cheese manufactured with this strain. Moreover, $L$. rhamnosus $\mathrm{H} 2$, which was able to utilize citrate in culture media, consumed citrate at the slowest rate in cheese and was unable to deplete the citrate present in the cheeses for the duration of the $90 \mathrm{~d}$ of ripening. The effect of environmental conditions on citrate utilization of L. casei ATCC334 was demonstrated by DíazMuñiz and Steele (2006), who found that citrate was utilized only when the galactose concentration was limiting in culture media, whereas when Cheddar cheese extract was used as the culture medium, citrate was utilized regardless of the galactose concentration. In

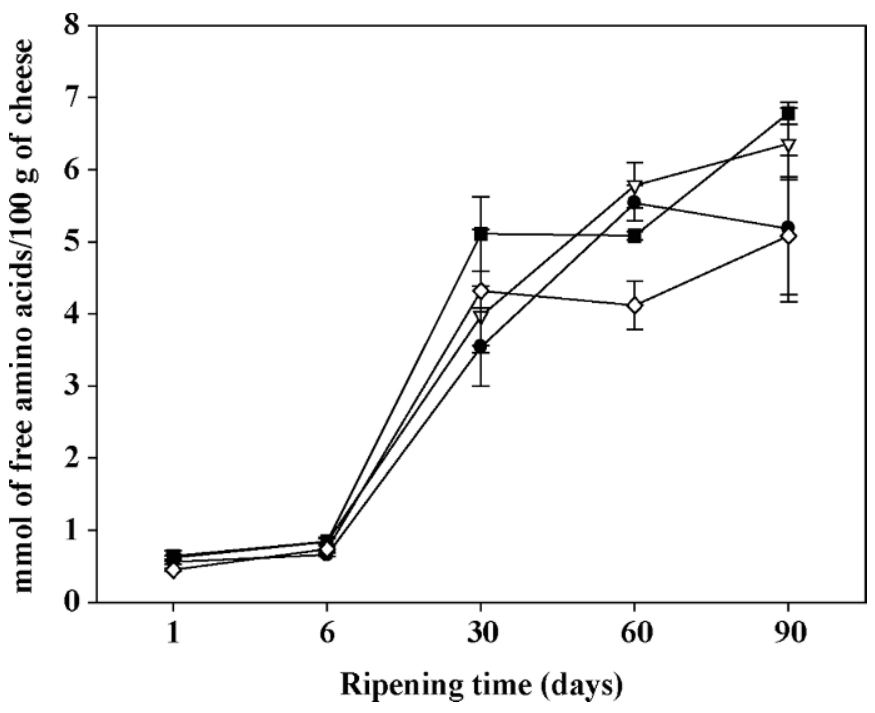

Figure 3. Changes in free amino acid concentration during ripening of cheeses manufactured with adjunct strains Lactobacillus casei A26 $(\nabla)$, L. casei B21 (ロ), Lactobacillus rhamnosus $\mathrm{H} 2(\diamond)$, and without adjunct $(\bullet)$. Error bars represent \pm standard error $(n=3)$. 

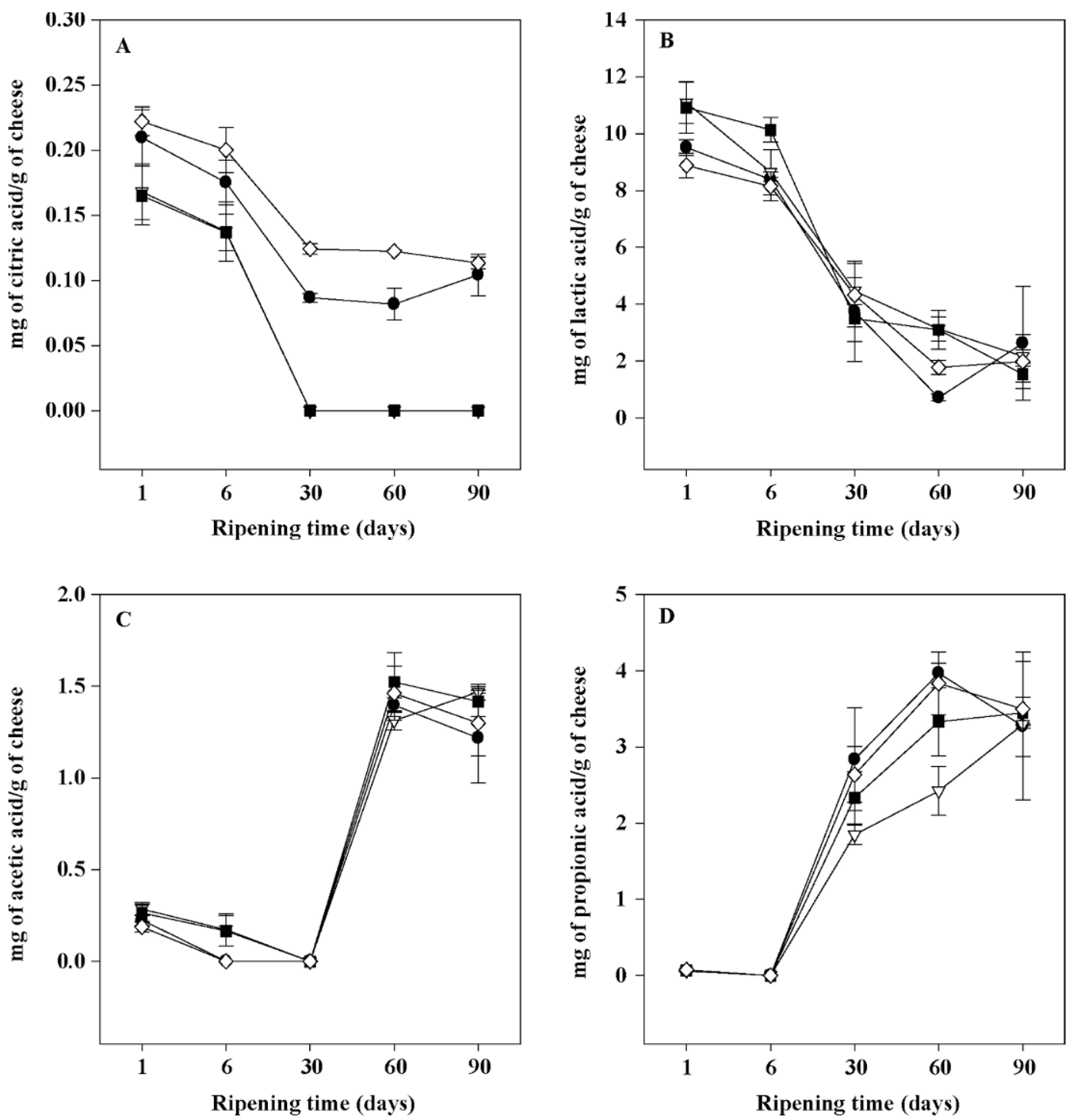

Figure 4. Changes in citric (A), lactic (B), acetic (C), and propionic (D) acids during ripening in cheeses manufactured with adjunct strains Lactobacillus casei A26 $(\nabla)$, L. casei B21 $(\mathbf{\square})$, Lactobacillus rhamnosus $\mathrm{H} 2(\diamond)$, and without adjunct $(\bullet)$. Error bars represent \pm standard error $(\mathrm{n}=3)$.

the same study, the presence of $2 \%$ sodium chloride in chemically defined culture media restricted the growth and affected citrate utilization by this strain. Conversely, cheese extract with a $4.5 \%$ salt-in-moisture content was not found to be inhibitory for citrate catabolism. Studies investigating the influence of $\mathrm{pH}$, monoand divalent cations, and carbohydrate type and concentration on citrate utilization of nonstarter lactic acid bacteria have reported contradictory observations, often resulting from the changes in experimental design and environmental conditions (Palles et al., 1998; DíazMuñiz and Steele, 2006). Our results support the evidence that citrate utilization by Lactobacillus spp. is strain dependent and strongly influenced by the environmental conditions.

The decrease in lactic acid and increase in acetic acid concentrations followed similar patterns in all cheeses during cheese ripening. Even though no significant differences in propionic acid concentrations were observed at $d 90$, cheeses differed in propionic acid levels at $d$ $60(P=0.051)$. The cheeses made with $L$. casei A26 had the lowest propionic acid level $(242 \mathrm{mg} / 100 \mathrm{~g})$, followed by L. casei $\mathrm{B} 21$ (333 mg/100 g), L. rhamnosus H2 (384 $\mathrm{mg} / 100 \mathrm{~g})$, and the control $(397 \mathrm{mg} / 100 \mathrm{~g})$. Others have reported lower propionic acid concentrations in Swisstype cheeses prepared with a citrate-utilizing Lactoba- 
cillus strain as an adjunct (Jimeno et al., 1995; Weinrichter et al., 2004a).

Average organic acid concentrations for 60-d-old good-quality Emmental cheeses are 500 to $800 \mathrm{mg}$ of propionate and 200 to $400 \mathrm{mg}$ of acetate per $100 \mathrm{~g}$ of cheese. In a variety of Swiss-type cheeses, concentrations of 293 to $656 \mathrm{mg}$ of propionic acid/100 $\mathrm{g}$ of cheese and 202 to $413 \mathrm{mg}$ of acetic acid/100 g of cheese were reported (Noël et al., 1999). Overall, the cheeses in the present study are on the low end of these ranges. The use of L. helveticus starter instead of Lactobacillus delbrueckii and the use of the lower cooking temperature may partially explain the lower values in comparison with published values for Emmental of a similar age. In theory, a propionic acid:acetic acid molar ratio of $2: 1$ is expected. The propionic acid:acetic acid molar ratios were $1.50,1.77,2.18$, and 2.31 for cheeses made with L. casei $\mathrm{A} 26, L$. casei $\mathrm{B} 21$, and $L$. rhamnosus $\mathrm{H} 2$ and for the control, respectively.

\section{Effect of Adjunct Cultures on Volatile Compounds Detected by Electronic Nose}

The formation of aroma in cheese is a complex process and is influenced to a great extent by cheese microflora (Marilley et al., 2004). Changes in the abundance of 3 mass units, 73, 85, and 87, are presented in Figure 5. Tentative identifications of compounds for each unit are propionic acid for mass 73 , diacetyl for mass 85 , and butyric/isobutyric acid for mass 87 . The control cheeses and cheeses manufactured with adjunct strain L. casei A26 were not significantly different for the abundance of the 3 mass units at the end of warm room ripening (d 30) and followed a similar pattern throughout ripening. There was no significant difference in propionic acid (mass 73) abundance among the cheeses at the end of ripening. However, at $\mathrm{d} 60$, cheeses manufactured with adjunct strain $L$. casei A26 had significantly lower $(P=0.002)$ propionic acid abundance than control cheeses. Cheeses made with adjunct strain L. rhamnosus $\mathrm{H} 2$ had more diacetyl and butyric/isobutyric acid than the other cheeses on 60 of ripening. The higher diacetyl content in cheeses made with adjunct strain $L$. rhamnosus $\mathrm{H} 2$ was unexpected. Diacetyl can be one of the end products of citrate metabolism. Citrate was not depleted in the L. rhamnosus $\mathrm{H} 2$ cheeses. Citrate was depleted in the $L$. casei A26 cheeses; however, they had low levels of diacetyl, similar to the control cheeses in which citrate was not depleted. In the present study, depletion of citrate did not necessarily correlate with an increase in diacetyl. The end products of citrate metabolism are complex and dependent on environmental conditions (Díaz-Muñiz and Steele, 2006). Although citrate is considered the main diacetyl precur-
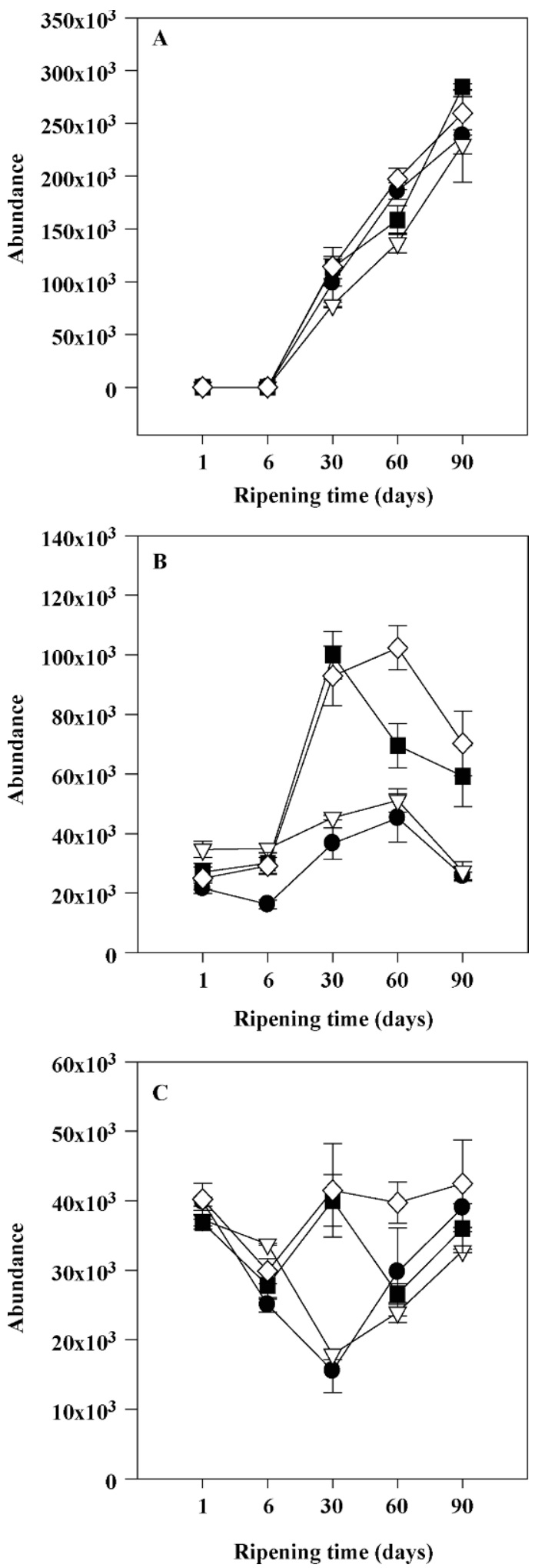

Figure 5. Changes in abundance of mass numbers 73-propionic acid (A), 85-diacetyl (B), and 87-butyric/isobutyric acid (C) during ripening in cheeses manufactured with adjunct strains Lactobacillus casei A26 $(\nabla)$, L. casei B21 (অ), Lactobacillus rhamnosus H2 $(\diamond)$, and without adjunct $(\bullet)$. Error bars represent \pm standard error $(n=3)$, 
Table 5. Descriptive sensory analysis scores ${ }^{1}$

\begin{tabular}{llllc}
\hline & \multicolumn{4}{c}{ Cheese $^{2}$} \\
\cline { 2 - 5 } Descriptor & A26 & B21 & H2 & Control \\
\hline Cooked/milky & $1.8^{\mathrm{b}}$ & $2.0^{\mathrm{a}}$ & $2.1^{\mathrm{a}}$ & $2.1^{\mathrm{a}}$ \\
Whey & $1.9^{\mathrm{a}}$ & $1.2^{\mathrm{bc}}$ & $1.4^{\mathrm{b}}$ & $1.0^{\mathrm{c}}$ \\
Milk fat & $2.1^{\mathrm{b}}$ & $2.1^{\mathrm{b}}$ & $2.4^{\mathrm{a}}$ & $2.5^{\mathrm{a}}$ \\
Vinegar & $1.8^{\mathrm{a}}$ & $1.3^{\mathrm{b}}$ & $1.7^{\mathrm{a}}$ & $1.6^{\mathrm{a}}$ \\
Dried fruit & $1.4^{\mathrm{a}}$ & $1.4^{\mathrm{a}}$ & $1.1^{\mathrm{b}}$ & $1.2^{\mathrm{ab}}$ \\
Sulfur/eggy & $0.6^{\mathrm{a}}$ & $0.5^{\mathrm{a}}$ & $0.5^{\mathrm{a}}$ & $0.6^{\mathrm{a}}$ \\
Sulfur/cabbage/ brothy & $2.4^{\mathrm{b}}$ & $2.2^{\mathrm{c}}$ & $2.5^{\mathrm{b}}$ & $2.8^{\mathrm{a}}$ \\
Free fatty acid/butyric acid & $0.4^{\mathrm{a}}$ & $0.3^{\mathrm{a}}$ & $0.4^{\mathrm{a}}$ & $0.4^{\mathrm{a}}$ \\
Nutty & $0.7^{\mathrm{b}}$ & $0.3^{\mathrm{c}}$ & $0.4^{\mathrm{c}}$ & $1.3^{\mathrm{a}}$ \\
Sweaty & $1.2^{\mathrm{b}}$ & $1.4^{\mathrm{ab}}$ & $1.2^{\mathrm{b}}$ & $1.6^{\mathrm{a}}$ \\
Sour & $1.7^{\mathrm{a}}$ & $1.5^{\mathrm{a}}$ & $1.2^{\mathrm{b}}$ & $1.3^{\mathrm{b}}$ \\
Sweet & $3.3^{\mathrm{b}}$ & $3.4^{\mathrm{ab}}$ & $3.3^{\mathrm{ab}}$ & $3.5^{\mathrm{a}}$ \\
Umami & $2.9^{\mathrm{a}}$ & $2.9^{\mathrm{a}}$ & $2.8^{\mathrm{a}}$ & $2.9^{\mathrm{a}}$ \\
\hline
\end{tabular}

${ }^{\mathrm{a}-\mathrm{c}}$ Means in the same row with the same letter are not significantly different $(P \geq 0.05)$.

${ }^{1}$ Attributes were scored using a 15-point universal intensity scale (Meilgaard et al., 1999). In previous studies, most cheese flavors fell between 0 and 7 (Drake et al., 2001). The attributes diacetyl, fresh fruit, bitter, salty, and prickle were not detected in the cheeses.

${ }^{2}$ Cheese manufactured with adjunct Lactobacillus casei A26, L. casei $\mathrm{B} 21$, Lactobacillus rhamnosus $\mathrm{H} 2$, or with no adjunct addition (control).

sor, the mechanisms by which diacetyl is formed in cheese are not completely understood (McSweeney and Sousa, 2000).

Electronic nose technology is a promising technology for rapid discrimination of cheeses based on volatile or aroma compounds. Electronic noses based on mass spectrometry have been used effectively to differentiate processed cheeses and Emmental cheeses from various European countries (Pillonel et al., 2003). This method has also been used successfully to discriminate among lactic acid bacteria at the strain level (Marilley et al., 2004). Our results further support the application of electronic nose technology for differentiating some cheeses differing in microbial population.

\section{Descriptive Sensory Analysis of Cheeses Prepared with Different Adjunct Cultures}

Treatment means for the 13 flavor attributes evaluated in the descriptive sensory analysis of 8-mo-old cheeses are shown in Table 5. None of the 4 treatments yielded the same sensory profile as another treatment; therefore, adjunct strains affected cheese flavor in a strain-dependent manner. The L. casei A26 and B21 and $L$. rhamnosus $\mathrm{H} 2$ cheeses differed from the control cheeses in 8, 5, and 4 of the 13 flavor attributes, respectively. The attributes diacetyl, fresh fruit, bitter, salty, and prickle were not detected in the cheeses. There were no significant differences in umami, sulfur/eggy, and free fatty acid/butyric acid flavors among the cheeses $(P \geq 0.05)$. There were significant differences in the intensities of the young undeveloped flavors (Drake et al., 2003), cooked and whey, between the control cheeses and the cheeses made with adjunct strain A26. Nutty flavor is an important characteristic of Swiss-type cheeses (Fröhlich-Wyder et al., 2002; Avsar et al. 2004). Cheeses made with adjunct cultures were less nutty than the control cheese. Cheese manufactured with adjunct strain L. casei A26 had a higher nutty note than cheeses manufactured with the other adjuncts. Adjunct-containing cheeses also had a slightly lower sulfur/cabbage/brothy flavor than control cheeses. The cheeses made with adjunct $L$. casei strains A26 and B21 had higher scores for sour and lower scores for milk fat flavor attributes compared with other cheeses. Although both sensory and chemical analysis differentiated the cheeses, the sensory and chemical data could not be correlated directly because of the difference in cheese age at the time of analysis $(8 \mathrm{mo}$ for sensory evaluation and up to $90 \mathrm{~d}$ for chemical evaluations).

Cheese flavor is influenced by the complex interactions of milk, coagulants, and manufacturing and ripening conditions, as well as the activity of starter, adjunct, and nonstarter populations. There are numerous reports on the effect of adjunct cultures on Cheddar cheese flavor. Several studies with experimental cheeses have indicated enhanced flavor formation when adjunct cultures are used (Tungjaroenchai et al., 2004; Whetstine et al., 2006), whereas some other studies have indicated reduced intensity of the desirable nutty and sulfur flavors (Broadbent et al., 2004). Studies on adjunct culture use in Swiss-type cheeses are limited and also provide variable conclusions. Weinrichter et al. (2004a, 2004b) reported an increased intensity of aroma or no significant effect, depending on the properties of the adjunct strains used. Fröhlich-Wyder et al. (2002) reported significantly lower sensory scores for texture and flavor for pilot-scale Emmental cheeses manufactured with the addition of a facultatively heterofermentative culture consisting of $3 \mathrm{~L}$. casei strains.

\section{CONCLUSIONS}

Selected nonstarter Lactobacillus strains isolated from commercial cheeses were used as adjunct cultures for Swiss cheese manufacture using the "kosher make procedure," which is commonly used for Swiss cheese manufacturing in the United States. Adjunct L. casei strains depleted citric acid by the end of the warm room ripening phase, whereas the adjunct $L$. rhamnosus strain did not. The rate at which each adjunct strain dominated the Lactobacillus population during ripening was strain dependent. Propionibacteria population and propionic acid levels were not significantly affected 
by adjunct strains during $90 \mathrm{~d}$ of ripening, with the exception of propionic acid levels at d 60, when $L$. casei A26 had lower propionic acid levels compared with control cheeses. Free amino acid concentrations, aroma compound content, and descriptive sensory scores were affected in an adjunct strain-dependent manner. The use of adjunct Lactobacillus cultures can provide Swiss cheese makers using a low cooking temperature with a means to control the dominant Lactobacillus strain during ripening, reduce citrate concentration, and modify cheese flavor.

\section{ACKNOWLEDGMENTS}

The authors acknowledge financial support from the Swiss Cheese Consortium (Columbus, OH), the Center for Innovative Food Technology at the Edison Industrial Systems Center (Toledo, OH), the J. T. Parker Chair in Dairy Foods (Columbus, OH), and a Graduate Student Research Competition Grant provided by the Ohio Agricultural Research and Development Center Research Enhancement Competitive Grants Program (Wooster, $\mathrm{OH}$ ). The authors thank Gary Wenneker and Mustafa Vurma for their technical support in the pilot plant.

\section{REFERENCES}

Agarwal, S., K. Sharma, B. G. Swanson, G. Ü. Yüksel, and S. Clark. 2006. Nonstarter lactic acid bacteria biofilms and calcium lactate crystals in Cheddar cheese. J. Dairy Sci. 89:1452-1466.

Antonsson, M., G. Molin, and Y. Ardö. 2003. Lactobacillus strains isolated from Danbo cheese as adjunct cultures in a cheese model system. Int. J. Food Microbiol. 85:159-169.

AOAC. 2005. Official Methods of Analysis. 18th ed. Assoc. Off. Anal. Chem., Gaithersburg, MD.

Avsar, Y. K., Y. Karagul-Yuceer, M. A. Drake, T. K. Singh, Y. Yoon, and K. R. Cadwallader. 2004. Characterization of nutty flavor in Cheddar cheese. J. Dairy Sci. 87:1999-2010.

Bachmann, H. P., U. Bütikofer, R. Badertscher, M. Dalla Torre, P. Lavanchy, U. Bühler-Moor, B. Nick, J. Jimeno, R. Warmke, W. Grosch, R. Sieber, and J. O. Bosset. 1997. Ripening of Emmental cheese wrapped in foil with and without addition of Lactobacillus casei subsp. casei: Microbial, chemical, rheological and sensorial investigations. Lebensm. Wiss. Technol. 30:417-428.

Baer, A., I. Ryba, J. Meyer, and U. Bütikofer. 1996. Microplate assay of free amino acids in Swiss cheeses. Lebensm. Wiss. Technol. 29:58-62.

Broadbent, J. R., S. Gummalla, J. E. Hughes, M. E. Johnson, S. A. Rankin, and M. A. Drake. 2004. Overexpression of Lactobacillus casei D-hydroxyisocaproic acid dehydrogenase in Cheddar cheese. Appl. Environ. Microbiol. 70:4814-4820.

Crow, V., B. Curry, and M. Hayes. 2001. The ecology of non-starter lactic acid bacteria (NSLAB) and their use as adjuncts in New Zealand Cheddar. Int. Dairy J. 11:275-283.

Dasen, A., F. Berthier, R. Grappin, A. G. Williams, and J. Banks. 2003. Genotypic and phenotypic characterization of the dynamics of the lactic acid bacterial population of adjunct-containing Cheddar cheese manufactured from raw and microfiltered pasteurised milk. J. Appl. Microbiol. 94:595-607.

Demarigny, Y., E. Beuvier, A. Dasen, and G. Duboz. 1996. Influence of raw milk microflora on the characteristics of Swiss-type cheeses. I. Evolution of microflora during ripening and charac- terization of facultatively heterofermentative lactobacilli. Lait 76:371-387.

Díaz-Muñiz, I., and J. L. Steele. 2006. Conditions required for citrate utilization during growth of Lactobacillus casei ATCC334 in chemically defined medium and Cheddar cheese extract. Antonie Van Leeuwenhoek 90:233-243.

Drake, M. A., and G. V. Civille. 2003. Flavor lexicons. Comp. Rev. Food Sci. Food Saf. 2:33-40.

Drake, M. A., P. D. Gerard, J. P. Kleinheinz, and W. J. Harper. 2003. Application of an electronic nose to correlate with descriptive sensory analysis of aged Cheddar cheese. Lebensm. Wiss. Technol. 36:13-20.

Drake, M. A., S. C. McIngvale, P. D. Gerard, K. R. Cadwallader, and G. V. Civille. 2001. Development of a descriptive language for Cheddar cheese. J. Food Sci. 66:1422-1427.

Folkertsma, B., and P. F. Fox. 1992. Use of the Cd-ninhydrin reagent to assess proteolysis in cheese during ripening. J. Dairy Res. 59:217-224.

Fröhlich-Wyder, M.-T., H. P. Bachmann, and M. G. Casey. 2002. Interaction between propionic acid bacteria and starter-/nonstarter lactic acid bacteria in Swiss-type cheeses. Lait 82:1-15.

Gagnaire, V., D. Mollé, M. Herrouin, and J. Léonil. 2001. Peptides identified during Emmental cheese ripening: Origin and proteolytic systems involved. J. Agric. Food Chem. 49:4402-4413.

Hunger, W. 1986. Asculin-Cellobiose-Agar für Isolierung und Keimzahlbestimmung von Lactobacillus acidophilus. Milchwissenschaft 41:283-285.

Ji, T., V. B. Alvarez, and W. J. Harper. 2004. Influence of starter culture ratios and warm room treatment on free fatty acid and amino acid in Swiss cheese. J. Dairy Sci. 87:1986-1992.

Jimeno, J., M. J. Lazaro, and H. Sollberger. 1995. Antagonistic interactions between propionic acid bacteria and non-starter lactic acid bacteria. Lait 75:401-413.

Kempler, G. M., and L. L. McKay. 1980. Improved medium for detection of citrate- fermenting Streptococcus lactis subsp. diacetylactis. Appl. Environ. Microbiol. 39:926-927.

Kieronczyk, A., S. Skeie, T. Langsrud, and M. Yvon. 2003. Cooperation between Lactococcus lactis and nonstarter lactobacilli in the formation of cheese aroma from amino acids. Appl. Environ. Microbiol. 69:734-739.

Kocaoglu-Vurma, N. A. 2005. Isolation and characterization of nonstarter Lactobacillus spp. in Swiss cheese and assessment of their role on Swiss cheese quality. PhD Diss. The Ohio State University, Columbus.

Kosikowski, F. V., and V. V. Mistry. 1997. Cheese with eyes. Pages 108-117 in Cheese and Fermented Milk Foods. Vol. 2. F. V. Kosikowski and V. V. Mistry, ed. Kosikowsi LLC, Westport, CT.

Lawrence, R. C., L. K. Creamer, and J. Gilles. 1987. Texture development during cheese ripening. J. Dairy Sci. 70:1748-1760.

Lynch, C. M., P. L. H. McSweeney, P. F. Fox, T. M. Cogan, and F. D. Drinan. 1997. Contribution of starter lactococci and nonstarter lactobacilli to proteolysis in Cheddar cheese with a controlled microflora. Lait 77:441-459.

Madec, M.-N., A. Rouault, J. L. Maubois, and A. Thierry. 1996. Selective medium containing lithium and a polyol or antibiotic for counting propionibacteria. Off. Gazette U. S. Patent Trademark Office Patents 1192(2):1226.

Marilley, L., S. Ampuero, T. Zesiger, and M. G. Casey. 2004. Screening of aroma-producing lactic acid bacteria with an electronic nose. Int. Dairy J. 14:849-856.

Marshall, R. T., ed. 1992. Standard Methods for the Examination of Dairy Products. 16th ed. Am. Public Health Assoc., Washington, DC.

Martley, F. G., and V. L. Crow. 1996. Open texture in cheese: The contributions of gas production by microorganisms and cheese manufacturing process. J. Dairy Res. 63:489-507.

McSweeney, P. L. H., and M. J. Sousa. 2000. Biochemical pathways for the production of flavour compounds in cheeses during ripening: A review. Lait 80:293-324.

Meilgaard, M. M., G. V. Civille, and B. T. Carr, eds. 1999. Descriptive analysis techniques. Pages 161-171 in Sensory Evaluation Techniques. 3rd ed. CRC Press, Boca Raton, FL. 
Noël, Y., P. Poyoval, A. Thierry, V. Gagnaire, and R. Grappin. 1999. Eye formation and Swiss-type cheeses. Pages 222-250 in Technology of Cheese Making. B. A. Law, ed. CRC Press, Boca Raton, FL.

Ortigosa, M., C. Arizcun, A. Irigoyen, M. Oneca, and P. Torre. 2006 Effect of Lactobacillus adjunct cultures on the microbiological and physicochemical characteristics of Roncal-type ewes'-milk cheese. Food Microbiol. 23:591-598.

Palles, T., T. Beresford, S. Condon, and T. M. Cogan. 1998. Citrate metabolism in Lactobacillus casei and Lactobacillus plantarum. J. Appl. Microbiol. 85:147-154.

Pillonel, L., S. Ampiero, R. Tabacchi, and J. O. Bosset. 2003. Analytical methods for the determination of the geographic origin of Emmental cheese: Volatile compounds by GC/MS-FID and electronic nose. Eur. Food Res. Technol. 216:179-183.

Poveda, J. M., L. Cabezas, and P. L. H. McSweeney. 2004. Free amino acid content of Manchego cheese manufactured with different starter cultures and changes throughout ripening. Food Chem. 84:213-218.

Reinbold, G. W. 1972. Swiss Cheese Varieties. Pfizer Inc., New York, NY.

Swearingen, P. A., D. J. O'Sullivan, and J. J. Warthesen. 2001. Isolation, characterization, and influence of native, nonstarter lactic acid bacteria on Cheddar cheese quality. J. Dairy Sci. 84:50-59.

Tungjaroenchai, W., C. H. White, W. E. Holmes, and M. A. Drake. 2004. Influence of adjunct cultures on volatile free fatty acids in reduced-fat Edam cheeses. J. Dairy Sci. 87:3224-3234.

Valence, F., S.-M. Deutsch, R. Richoux, V. Gagnaire, and S. Lortal 2000. Autolysis and related proteolysis in Swiss cheese for two Lactobacillus helveticus strains. J. Dairy Res. 67:261-271.

Valence, F., R. Richoux, A. Thierry, A. Palva, and S. Lortal. 1998. Autolysis of Lactobacillus helveticus and Propionibacterium freudenreichii in Swiss cheeses: First evidence by using speciesspecific lysis markers. J. Dairy Res. 65:609-620.

Weinrichter, B., W. Ginzinger, H. Sollberger, and H. Rohm. 2004b. Production of Emmental cheese with adjunct starters with varying degree of autolysis. Milchwissenshaft 59:515-519.

Weinrichter, B., H. Sollberger, W. Ginzinger, D. Jaros, and H. Rohm. 2004a. Adjunct starter properties affect characteristic features of Swiss-type cheeses. Nahrung/Food 48:73-79.

Whetstine, M. E., M. A. Drake, J. R. Broadbent, and D. McMahon. 2006. Enhanced nutty flavor formation in Cheddar cheese made with a malty Lactococcus lactis adjunct culture. J. Dairy Sci. 89:3277-3284. 